\title{
EFEITO DA ÁGUA DISPONÍVEL DO SOLO NO DESENVOLIMENTO DE DOIS CULTIVARES DE MAMONA, NOS PRIMEIRO E SEGUNDO CICLOS ${ }^{1}$
}

\section{LEOBERTO DE A. FORMIGA ${ }^{2}$, HUGO O. C. GUERRA ${ }^{3}$, ROGÉRIO D. DE LACERDA ${ }^{4}$, JOSÉ E. BARBOSA DA SILVA ${ }^{5}$, MARIO S. ARAUJO ${ }^{6}$}

RESUMO: A mamoneira é uma oleaginosa de relevante importância econômica e social, de grande relevância para a economia da região Nordeste, por fixar mão de obra, evitando a evasão de divisas. Foram estudados diferentes aspectos do manejo da cultura da mamona, visando à otimização do uso da água e do rendimento da mamona, no primeiro e segundo ciclos de produção, sendo este último obtido após uma drástica poda da planta no final do primeiro ciclo. A pesquisa foi desenvolvida no campo em Lagoa Seca-PB. O delineamento experimental foi o de blocos ao acaso, em esquema fatorial 2 x 4, constituído com duas cultivares de mamona (BRS 149 - Nordestina e o BRS 188 Paraguaçu) e quatro níveis de água disponível no solo (40; 60; 80 e 100\%), distribuídos em três blocos. Os dados foram submetidos à análise de variância F. A altura da planta, o diâmetro do caule, a área foliar e a fitomassa da parte aérea foram avaliados. O acréscimo da disponibilidade hídrica no solo aumentou todos os índices de crescimento e/ou desenvolvimento das plantas. O segundo ciclo da cultura apresentou comportamento semelhante ao do primeiro ciclo, demonstrando a viabilidade técnica de condução a um segundo ciclo da mamona.

PALAVRAS-CHAVE: Manejo de poda, Manejo da irrigação, Ricinus communis L.

\section{EFFECT OF AVAILABLE SOILWATER IN THE DEVELOPMENT OF TWO CASTOR BEAN CULTIVARS IN THE FISRT AND SECONDCYCLES}

\begin{abstract}
Castor bean is an oleaginous of relevant economic and social importance. It is a very important culture for the economy of the Northeast of Brazil due to its social inclusion, employment and devises guaranty. In the present research was studied different castor bean management aspects, aiming the optimization of water use and crop yields in the first and second cycles, being this last one obtained after a drastic pruning of the plant at the end of the first cycle. The experiment was conducted at the field in Lagoa Seca, PB. The experimental design was a randomized block in a factorial 2 x 4 scheme, consisting of two castor bean cultivars (BRS 188 - Paraguaçu and BRS 149 Nordestina) and 4 levels of available soil water (40,60, 80, and 100\%) with three replicates. The data was analyzed statistically through analysis of $\mathrm{F}$ variance. Plant height, stem diameter, leaf area and phytomass of shoots were evaluated. Available soil water increased all growth and development indices of the plants. The second cycle of the culture (regrowth), presented behavior similar to that observed in the first cycle, demonstrating the technical feasibility of conducting a second cycle of Castor bean.
\end{abstract}

KEYWORDS: Pruning management, Irrigation management, Ricinus communis L.

\footnotetext{
${ }^{1}$ Parte da Tese de Doutorado do primeiro autor.

${ }^{2}$ Eng $^{\circ}$ Agrícola, Prof. Dr., Depto. de Agroecologia e Agropecuária, CCAA/UEPB/Lagoa Seca-PB, Fone: (83) 3337-1865, leobertoformiga@uol.com.br.

${ }^{3}$ Eng $^{\circ}$ Agrônomo, Ph.D. Prof. Titular, Unidade Acadêmica de Eng. Agrícola, UFCG, Campina Grande-PB, hugo_carvallo@hotmail.com.

${ }^{4}$ Eng $^{\circ}$ Agrícola, Prof. Dr., Instituto Federal de Educação, Ciência e Tecnologia do Rio Grande do Norte, Campus Apodi, IFRN/Apodi-RN, rogerio_dl@yahoo.com.br.

${ }^{5}$ Eng $^{\circ}$ Agrícola, Dr. Bolsista do CNPq, Unidade Acadêmica de Engenharia Agrícola, UFCG, Campina GrandePB,joseeverardo@hotmail.com

${ }^{6}$ Eng $^{\circ}$ Agrícola, Prof. Doutor, Departamento de Agroecologia e Agropecuária, CCAA/UEPB/Lagoa SecaPB,mariosaraujo@hotmail.com. 


\section{INTRODUÇÃO}

O cultivo da mamona tem-se intensificado devido à utilização de seu óleo na indústria de bicombustíveis. Várias indústrias de extração de óleo e produção do biodiesel estão em fase de adaptação ou de construção (BELTRÃO et al., 2007).

No Nordeste do Brasil, em especial no Semiárido, a mamona tem-se mostrado altamente promissora por sua fácil adaptação ao clima da região. Segundo LACERDA et al. (2009), a demanda hídrica da mamona varia entre 750 e $1.500 \mathrm{~mm}\left(7.500\right.$ a $\left.15.000 \mathrm{~m}^{3} . \mathrm{ha}^{-1}\right)$. O plantio deve ser programado de forma que a planta receba de 400 a $500 \mathrm{~mm}$ até o início da floração. Quando o solo é mantido à capacidade de campo (100\% de água disponível), com manejo e aplicação de insumos necessários ao desenvolvimento da cultura, a mamoneira transforma os insumos em produção efetiva de matéria seca e, consequentemente, em maior produção de frutos por área cultivada (BARROS JÚNIOR et al., 2008). Segundo DINIZ NETO et al. (2009), a mamoneira é exigente em umidade nos estádios iniciais de seu crescimento, necessitando de um período seco nos estádios de maturação e secagem dos frutos.

O potencial de produção da mamona deve-se, em grande parte, às características das cultivares utilizadas. A análise de crescimento da mamoneira possibilita identificar diferenças entre as cultivares e permite estabelecer relações entre a planta e o ambiente, por meio dos parâmetros fisiológicos e elementos climáticos, edáficos e fitotécnicos (CRUZ et al., 2010; SAMPAIO FILHO, 2011). O déficit hídrico afeta o desenvolvimento vegetal por meio de efeitos sobre a abertura estomática, o processo fotossintético e o crescimento, sendo que cada um destes processos pode ser afetado diferentemente, dependendo do genótipo da planta e da intensidade do déficit hídrico (MEDICI et al., 2007; OLIVEIRA et al., 2009; BARRETO et al., 2010; FREITAS et al., 2010).

A poda drástica da planta após o final do primeiro ciclo possibilita um segundo ciclo de produção, sem necessidade de erradicação da cultura, novo preparo de solo, aquisição de novas sementes, dentre outros (AZEVEDO et al., 2007).

O objetivo do presente trabalho foi avaliar o desempenho de duas cultivares de mamoneira, submetidas a diferentes teores de água disponível do solo, em primeiro e segundo ciclos de 180 dias cada, na região do Agreste Paraibano.

\section{MATERIAL E MÉTODOS}

O experimento foi realizado em condições de campo, no Centro de Ciências Agrárias e Ambientais da Universidade Estadual da Paraíba - UEPB, Câmpus II, Lagoa Seca - PB, com coordenadas geográficas $7^{\circ} 15^{\prime} 18^{\prime}$ ' S e $35^{\circ} 52^{\prime} 28^{\prime}$ ' W, altitude média de $634 \mathrm{~m}$. O período chuvoso é concentrado entre abril e julho, com precipitação pluvial anual média de $800 \mathrm{~mm}$, temperatura do ar entre $18^{\circ}$ e $33^{\circ} \mathrm{C}$ e umidade relativa do ar em torno de $80 \%$. O clima da área, segundo a classificação de Köppen, é do tipo As' (tropical úmido) com estação seca translocada do inverno para o outono.

O solo da área experimental é classificado como Neossolo Regolítico eutrófico. A área recebeu uma gradagem em junho e julho de 2008, quando foram coletadas amostras compostas na profundidade de 20 centímetros da superfície, para se determinar as características físico-hídricas do solo de acordo com metodologia recomendada pela EMBRAPA (1997) (Tabela 1).

TABELA 1 - Características físico-hídricas do solo. Physical Characteristics of the soil.

\begin{tabular}{|c|c|c|c|c|c|c|c|c|c|}
\hline \multicolumn{4}{|c|}{ Textura } & \multicolumn{2}{|c|}{ Densidade } & Porosidade & \multicolumn{3}{|c|}{ Conteúdo de água do solo } \\
\hline $\begin{array}{l}\text { Argila } \\
\text { g. } \mathrm{kg}^{-1}\end{array}$ & $\begin{array}{l}\text { Silte } \\
\text { g. } \mathrm{kg}^{-1}\end{array}$ & $\begin{array}{l}\text { Areia } \\
\text { g. } \mathrm{kg}^{-1}\end{array}$ & $\begin{array}{c}\text { Classificação } \\
\text { Textural* }\end{array}$ & Solo & Partícula & $\mathrm{m}^{3} \cdot \mathrm{m}^{-3}$ & $\begin{array}{c}\text { CC } \\
\mathrm{m}^{3} \cdot \mathrm{m}^{-3} \\
\end{array}$ & $\begin{array}{c}\text { PMP } \\
\mathrm{m}^{3} \cdot \mathrm{m}^{-3}\end{array}$ & $\begin{array}{c}\mathrm{AD} \\
\mathrm{m}^{3} \cdot \mathrm{m}^{-3}\end{array}$ \\
\hline 113,9 & 114,5 & 771,6 & Franco-arenoso & 1,34 & 2,65 & 0,4943 & 0,1942 & 0,0896 & 0,1046 \\
\hline
\end{tabular}


O plantio das cultivares de mamona 149 - Nordestina e o BRS 188 - Paraguaçu foi realizado em curvas de nível do terreno, a uma profundidade de semeadura entre 2 e $3 \mathrm{~cm}$, lançando-se na operação de semeio duas sementes por cova. O solo foi adubado com superfosfato triplo no plantio, com $120 \mathrm{~kg} / \mathrm{ha}$ de $\mathrm{P}_{2} \mathrm{O}_{5}$, e em cobertura com $100 \mathrm{~kg} / \mathrm{ha}$ de $\mathrm{K}_{2} \mathrm{O}$ e de $\mathrm{N}$, via fertirrigação, nas formas de cloreto de potássio e ureia, divididos em intervalos de 10 dias, a partir de 20 dias após a semeadura (DAS). A adubação para o segundo ciclo foi executada nas mesmas quantidades e seguindo a mesma forma de aplicação do primeiro ciclo.

Aos 20 DAS, foi realizado um desbaste, deixando-se apenas as duas plantas mais vigorosas por cova, e aos 30 DAS, um segundo desbaste foi realizado, deixando-se uma planta por cova.

As lâminas de irrigação aplicadas às cultivares de mamona foram baseadas em resultados de estudos realizados anteriormente em casa de vegetação com estas mesmas cultivares (BARROS JÚNIOR et al., 2008; LACERDA et al., 2009), com diferentes níveis de água disponível no solo para as plantas. Cada tratamento teve um sistema de distribuição de água independente. As aplicações de água foram diferenciadas pelo tempo de aplicação, utilizando-se de registros de volume de água.

As irrigações foram feitas por gotejamento, quando o conteúdo de água do solo atingiu os valores preestabelecidos pelos respectivos tratamentos (40; 60; 80 e $100 \%$ da água disponível). O conteúdo de água do solo nos intervalos de profundidades de $0-10 ; 10-20 ; 20-30$ e 30-40 cm foi monitorado a cada dois dias, utilizando-se de uma sonda de TDR segmentada, modelo HH2 PR1/6, de marca DELTA-T DEVICES, inserida no solo por meio de um tubo de acesso instalado em cada parcela. Os dados foram processados numa planilha do Microsoft Excel, realizando-se um balanço do conteúdo de água do perfil do solo, determinando, assim, o volume de água total a ser reposto pela irrigação, com base na equação da água disponível no solo (BERNARDO, 2008).

Aos 180 DAS, foi realizada uma poda drástica, cortando-se as plantas a $30 \mathrm{~cm}$ do colo (tomando-se como base a superfície do solo), o que deu início ao segundo ciclo de cultivo. Foram realizadas medidas da altura da planta, medida por meio de uma trena, do colo da planta à base da folha mais jovem; do diâmetro do caule, medido com um paquímetro, na região do colo; da área foliar, nas folhas com comprimento mínimo de 3,0 cm, calculada pelo método de WENDT (1967), de acordo com a [eq. (1)]:

$$
\sum_{i=1}^{n} \operatorname{LOG}(Y)=\sum_{i=1}^{n}\{-0,346+[2,152 * \operatorname{LOG}(X)]\}
$$

em que:

$$
\begin{aligned}
& \mathrm{Y}=\text { área foliar }\left(\mathrm{cm}^{2}\right) ; \\
& \mathrm{X}=\text { comprimento da nervura central da folha }(\mathrm{cm}) ; \\
& \mathrm{n}=\text { número de folhas. }
\end{aligned}
$$

As folhas, os caules, os ramos, as inflorescências e os cachos foram coletados e colocados para secagem em uma estufa de circulação de ar forçado a uma temperatura de $60{ }^{\circ} \mathrm{C}$, até atingir peso constante, para a determinação da fitomassa seca.

Aos 180 dias após a poda (DAP), no fim do segundo ciclo, as mesmas avaliações voltaram a ser realizadas.

O delineamento experimental utilizado neste ensaio foi o de blocos ao acaso, no esquema fatorial 2 x 4, constituído pelas 2 cultivares de mamona e 4 níveis de água disponível do solo, e em 3 blocos. Cada bloco, com 10 x $80 \mathrm{~m}$, foi constituído por 8 parcelas, com uma área total de $100 \mathrm{~m}^{2} \mathrm{e}$ uma área útil de $48 \mathrm{~m}^{2}$, onde foram cultivadas 50 plantas, espaçadas em $2 \mathrm{~m} \mathrm{x} 1 \mathrm{~m}$, com 24 plantas úteis e 26 de bordadura. O cultivo ocupou uma área total de 0,24 hectare. 
Os dados foram analisados estatisticamente, utilizando-se do programa estatístico SISVAR, através do qual foram feitas as análise de variância e o teste de Tukey, a 5 \% de probabilidade para a comparação das médias dos tratamentos qualitativos e análise de regressão para o fator quantitativo, de acordo com SANTOS et al. (2008).

\section{RESULTADOS E DISCUSSÃO}

\section{Altura de Plantas - AP}

Os resultados de análise de variância (Tabela 2) demonstram que não houve diferença significativa em ambos os ciclos entre as cultivares de mamona quanto à altura de plantas e diâmetro de caule, quando submetidas a diferentes níveis de água disponível no solo. A altura de plantas no segundo ciclo foi menor, com uma diferença entre o primeiro e o segundo ciclos de 37,83 para a cv Nordestina e 36,34 cm para a cv Paraguaçu.

TABELA 2 - Resumo da análise de variância da altura da planta e diâmetro do caule das cultivares de mamona BRS 149-Nordestina e BRS 188-Paraguaçu, no primeiro e segundo ciclos de produção, submetidas a diferentes níveis de água disponível no solo (AD). Summary of analysis of variance of plant height and stem diameter for castor bean cv. BRS 149-Nordestina and BRS 188-Paraguaçu, in the first and second cycles, cropped under different levels of available soil water.

\begin{tabular}{|c|c|c|c|c|c|}
\hline \multirow{3}{*}{ Fonte de variação } & & \multicolumn{2}{|c|}{ Altura da planta } & \multicolumn{2}{|c|}{ Diâmetro do caule } \\
\hline & & \multicolumn{4}{|c|}{ Quadrado médio } \\
\hline & GL & $1^{\circ}$ Ciclo & $2^{\circ}$ Ciclo & $1^{\circ}$ Ciclo & $2^{\circ}$ Ciclo \\
\hline Cultivar & 1 & $112,67^{\mathrm{ns}}$ & $204,17^{\mathrm{ns}}$ & $57,35^{\mathrm{ns}}$ & $25,83^{\mathrm{ns}}$ \\
\hline Água disponível & 3 & $12.130,066^{* *}$ & $4.439,00 *$ & $661,88^{* *}$ & $694,33^{* *}$ \\
\hline Água disponível x cultivar & 3 & $132,56^{\text {ns }}$ & $23,83^{\text {ns }}$ & $16,41^{\mathrm{ns}}$ & $39,83^{\mathrm{ns}}$ \\
\hline Blocos & 2 & $846,13^{\text {ns }}$ & $270,04^{\mathrm{ns}}$ & $17,03^{\mathrm{ns}}$ & $332,85^{\mathrm{ns}}$ \\
\hline Resíduo & 14 & 266,55 & 978,61 & 36,07 & 125,90 \\
\hline$\overline{\mathrm{CV}(\%)}$ & & 7,71 & 17,91 & 11,84 & 16,77 \\
\hline Regressão Polinomial Linear & & $36.261,63^{* *}$ & $12.979,20^{* *}$ & $1.822,86^{* *}$ & $2.022,94^{* *}$ \\
\hline Regressão Polinomial Quadrática & & $24,00^{\mathrm{ns}}$ & $160,17^{\mathrm{ns}}$ & $162,76^{\mathrm{ns}}$ & $13,05^{\text {ns }}$ \\
\hline Regressão Polinomial Cúbica & & $104,53^{\mathrm{ns}}$ & $177,63^{\mathrm{ns}}$ & $0,01^{\mathrm{ns}}$ & $47,00^{\mathrm{ns}}$ \\
\hline Resíduo & & 266,55 & 978,61 & 36,04 & 125,90 \\
\hline Cultivares & & \multicolumn{2}{|c|}{ Altura das plantas (cm) } & \multicolumn{2}{|c|}{ Diâmetros do caule (mm) } \\
\hline Nordestina & & $209,58 \mathrm{a}$ & $171,75 a$ & 49,15 a & 65,87 a \\
\hline Paraguaçu & & 213,92 a & $177,58 a$ & $52,24 \mathrm{a}$ & $67,94 \mathrm{a}$ \\
\hline DMS & & 14,30 & 27,39 & 5,26 & 9,82 \\
\hline
\end{tabular}

GL - grau de liberdade; significativo a $0,05\left(^{*}\right)$ e a $0,01\left(^{* *}\right)$ de probabilidade; (ns) não significativo; CV - coeficiente de variação; DMS - diferença mínima significativa; médias seguidas de mesma letra na vertical não diferem entre si $(\mathrm{p}<0,05)$.

Houve efeito significativo dos níveis de água disponível do solo sobre a altura das plantas, ao nível de $1 \%$ de probabilidade $(\mathrm{p}<0,01)$, no primeiro ciclo. Com base nas plantas cujo solo foi mantido à capacidade de campo (100\% de AD), a altura média foi de 263,83 no primeiro ciclo e verificou-se, pelo teste de comparação de médias, que aos 180 DAS, no final do primeiro ciclo, as diferenças foram 40,24; 24,89 e 13,83\% superiores aos tratamentos com 40; 60 e 80\% de AD. No segundo ciclo, houve diferença significativa ao nível de $5 \%(\mathrm{p}<0,05)$ na altura das plantas; em condições de rebrote, apresentou um porte inferior $(209,67 \mathrm{~cm})$. RODRIGUES et al. (2009), trabalhando com diferentes níveis de irrigação, em casa de vegetação, encontrou alturas médias aos 150 dias após a semeadura, para as cultivares Nordestina e Paraguaçu, de 136,01 e 148,80 cm, respectivamente. A redução do conteúdo de água do solo afetou a altura, o diâmetro do caule e a área foliar das plantas. Assim, quando a cultura da mamona fica no campo exposta a deficiências hídricas, a suplementação hídrica por meio da irrigação, nas épocas de maior demanda de água pela 
cultura, possibilita melhor desenvolvimento da cultura. SAMPAIO FILHO et al. (2011) avaliaram quatro cultivares de mamoneira nas condições agroecológicas do Recôncavo Baiano e destacaram que a altura da planta de uma espécie é determinada, entre outros fatores, pelo suprimento de água.

As curvas de regressão e suas respectivas equações podem ser observadas na Figura 1. Notase que o aumento da altura, além de linear, evolui de forma crescente com o avanço do ciclo, variando de $1,74 \mathrm{~cm}$ por aumento unitário do percentual de água no solo, em volume, aos 180 DAS, no final do primeiro ciclo, a $1,04 \mathrm{~cm}$ por aumento unitário do percentual de água no solo, em volume, aos 180 DAP ao final do segundo ciclo, com diferença entre primeiro e segundo ciclos de $0,7 \mathrm{~cm}$ com um percentual a mais no primeiro ciclo, de 40\%. Esta tendência também foi constatada por BARROS JÚNIOR et al. (2008) ao testarem diferentes níveis de água disponível do solo (40; 60; 80 e 100\%), em casa de vegetação, para estas mesmas cultivares de mamona, e os autores encontraram incrementos de $1,75 \mathrm{~cm}$ por aumento unitário do percentual de água no solo, em volume, aos 180 DAS, no final do primeiro ciclo. BARROS JÚNIOR et al. (2008) constataram que a altura média final (180 DAS) das plantas cultivadas sem estresse (100\% de água disponível - AD), em casa de vegetação, chegou a 1,28 m. NASCIMENTO et al. (2004) e SILVA et al. (2008) também verificaram ajustes da altura da mamoneira ao modelo linear, aumentando o crescimento das plantas em função da aplicação de água residuária, ao longo do tempo.

LACERDA (2010), em experimento de campo, encontrou alturas de plantas iguais a 2,28 e 2,60 m para os tratamentos com 5,0 e 25,0 g. $\mathrm{kg}^{-1} \mathrm{de} \mathrm{MO}$ (matéria orgânica), aos 180 DAS, no primeiro ciclo, e 2,33 e $2,83 \mathrm{~m}$ no segundo ciclo, com o solo a $100 \%$ de AD para os tratamentos com 5,0 e 25,0 g. $\mathrm{kg}^{-1}$ de MO e com os nutrientes do solo necessários ao bom desenvolvimento da cultura da mamona.

Ainda LACERDA (2010), em pesquisa de campo com a cultivar BRS 188-Paraguaçu, encontrou variações de 2,20 e 2,37 cm na altura da planta por aumento unitário do percentual de água no solo, aos 180 DAS, para os tratamentos com 5,0 e 25,0 g. $\mathrm{kg}^{-1} \mathrm{de} \mathrm{MO}$, respectivamente, no primeiro ciclo; para o segundo ciclo, o aumento unitário da altura da planta foi 3,0 e 4,42 cm para os tratamentos com 5,0 e 25,0 g. $\mathrm{kg}^{-1}$ de MO, respectivamente, aos180 DAP.

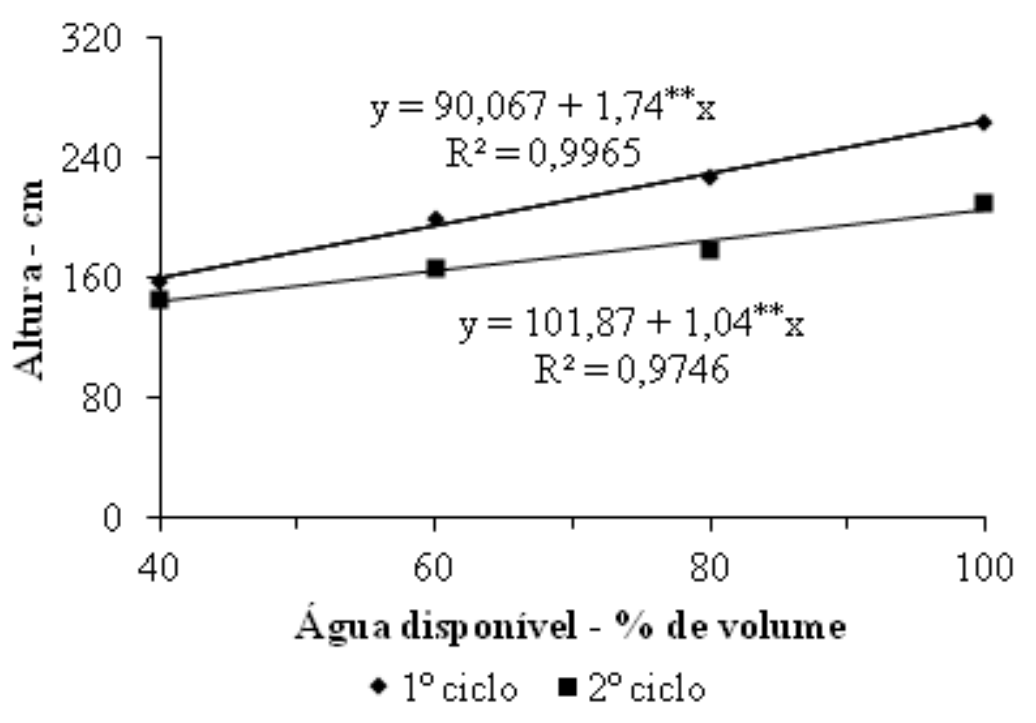

FIGURA 1. Altura da mamoneira em função da água disponível no solo. Plant height of Castor bean versus available soil water. 


\section{Diâmetro do caule (DC)}

Com o tratamento mantido a 100\% de AD, aos 180 DAS, o diâmetro médio do caule foi de 64,98 mm. Ao final do ciclo, com esse mesmo tratamento, os diâmetros do caule apresentaram-se 1,25 vez superior aos diâmetros dos caules de plantas cujo tratamento foi de 80 \% de AD; 1,47 vez superior aos diâmetros de plantas com tratamento a 60 \% de AD; e 1,56 vez superior aos diâmetros de plantas com tratamento a $40 \%$ de AD. Desse resultado, deduz-se que plantas cultivadas sem restrição hídrica devem ser mais resistentes ao tombamento, devido a caules mais robustos. Já no segundo ciclo, as plantas mantidas a 100\% AD, aos180 DAP, apresentaram diâmetro médio do caule de 79,33mm, e 1,42; 1,32 e 1,10 vez superior aos diâmetros, cujas plantas foram mantidas a 40; 60 e 80\% AD, respectivamente. A diferença dos valores obtidos dos diâmetros entre os dois ciclos a $100 \%$ de AD foi igual a $18,10 \%$ a mais no segundo ciclo, conforme Tabela 2 . Esta diferença deve-se ao caule não ter sido suprimido após a poda, mas a uma altura de $30 \mathrm{~cm}$ da base, portanto continuando a crescer, já com raízes formadas, e os assimilados contidos nessa fração do caule passam a fornecer nutrientes para as novas ramificações, a partir do rebrote.

As regressões apresentam tendência de crescimento linear no diâmetro do caule das plantas. Observa-se, através da Figura 2, que o aumento no diâmetro do caule também evoluiu de forma crescente com 0,39 mm por aumento unitário do percentual de água no solo, em volume, aos 180 DAS no primeiro ciclo. No segundo ciclo, a evolução do diâmetro foi de $0,41 \mathrm{~mm}$ no diâmetro da planta por aumento unitário do percentual de água no solo, em volume, aos 180 DAP. A diferença entre os dois ciclos foi de $0,02 \mathrm{~mm}$, a maior para o segundo ciclo.

RODRIGUES et al. (2009) observaram diâmetro caulinar médio superior a 32,0 mm, maior que os 23,0 mm obtidos por BARROS JÚNIOR et al. (2008), em estudo similar, porém com água de abastecimento cuja grande diferença pode ser atribuída ao aporte de nutrientes da água residuária. LACERDA et al. (2009) observaram, aos 120 dias da semeadura, diâmetro caulinar

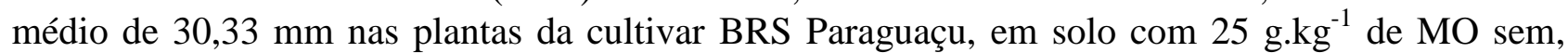
entretanto, diferir do diâmetro das plantas cultivadas em solo contendo 5 g. $\mathrm{kg}^{-1}$ de MO (28,75 mm). LACERDA (2010) concluiu também que o aumento no diâmetro do caule também evolui de forma crescente com o avanço do ciclo da cultura até os 180 DAS e DAP, na condição de 5,0 e 25,0 g kg de MO.

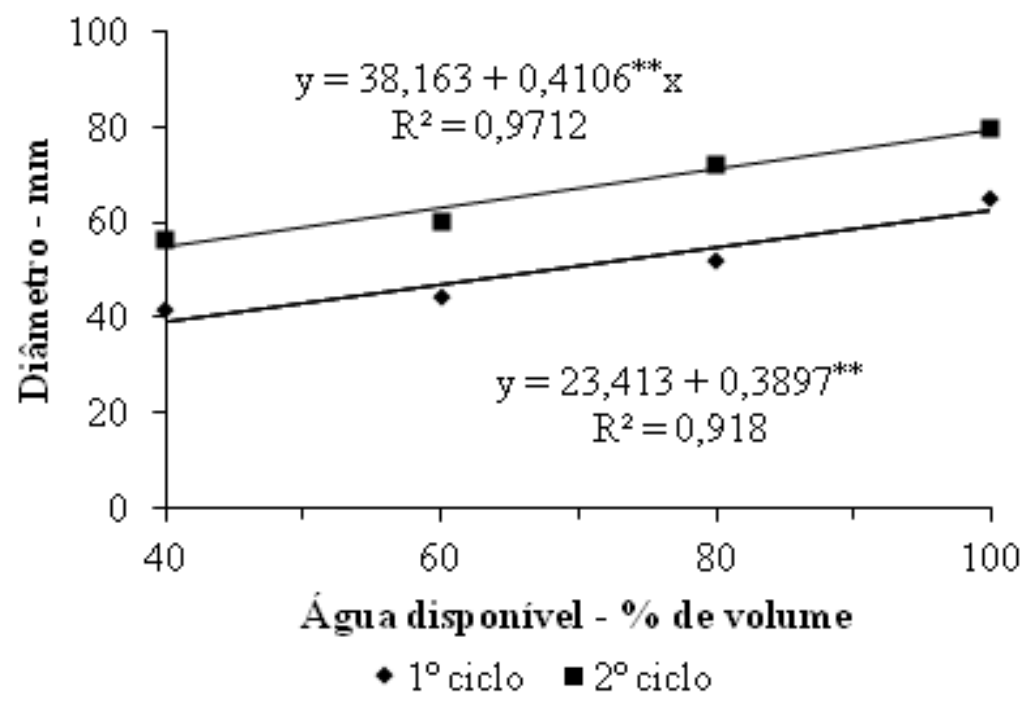

FIGURA 2. Diâmetro do caule em função da água disponível no solo. Stem diameter of Castor bean versus available soil water. 


\section{Área Foliar (AF)}

Não houve diferenças estatísticas significativas para a área foliar (AF), entre as duas cultivares, conforme observado na Tabela 3. No entanto, foram observados efeitos significativos na área foliar, em função dos diferentes níveis de $\mathrm{AD}(40 ; 60 ; 80$ e $100 \%$ de $\mathrm{AD}$ ) a nível de $1 \%$ (P < 0,01), aos 180 DAS.

A área foliar das plantas submetidas a $100 \%$ de $\mathrm{AD}\left(3,74 \mathrm{~m}^{2}\right)$, quando comparada aos níveis de 40; 60 e 80\% de AD, foi, respectivamente, 37,43; 31,82 e 7,22\%, aos 180 DAS. Verifica-se que as plantas submetidas a $100 \%$ de $\mathrm{AD}\left(3,74 \mathrm{~m}^{2}\right)$ tiveram sua área foliar superior em 41,71; $29,95 \mathrm{e}$ $7,75 \%$ à das plantas submetidas a $40 ; 60$ e $80 \%$ de $A D$, respectivamente. Esses resultados apresentam-se semelhantes nas duas fases do experimento, demonstrando o vigor das cultivares estudadas também em condições de rebrote. A redução da área foliar com a AD do solo, encontrada no presente trabalho, pode ter sido influenciada pelas condições de estresse hídrico, pois, segundo afirmam BELTRÃO et al. (2007), em plantas de mamona sob condições de estresse hídrico, a divisão e a expansão celular são afetadas, causando a maturação das folhas em tamanhos menores. Além disso, ocorreu declínio na condutância estomática devido ao aumento da densidade de estômatos nas folhas de plantas estressadas.

TABELA 3 - Resumo da análise de variância referente à variável área foliar (AF) e fitomassa da parte aérea (FT) das cultivares de mamona BRS 149-Nordestina e BRS 188Paraguaçu, em $1^{\circ}$ e $2^{\circ}$ ciclos quando submetidas a diferentes níveis de água disponível no solo (AD). Summary of analysis of variance of the leaf area (AF) and phytomass (FT) for castor bean cv. BRS 149-Nordestina and BRS 188Paraguaçu, in the first and second cycles, cropped under different levels of available soil water (AD).

\begin{tabular}{|c|c|c|c|c|c|}
\hline \multirow{2}{*}{\multicolumn{2}{|c|}{ Fonte de variação }} & \multicolumn{2}{|c|}{ Área foliar } & \multicolumn{2}{|c|}{ Fitomassa da parte aérea } \\
\hline & & \multicolumn{4}{|c|}{ Quadrado médio } \\
\hline & GL & $1^{\circ}$ Ciclo & $2^{\circ}$ Ciclo & $1^{\circ}$ Ciclo & $2^{\circ}$ Ciclo \\
\hline Cultivar & 1 & $0,96^{\mathrm{ns}}$ & $0,49^{\mathrm{ns}}$ & $49.847,20^{\mathrm{ns}}$ & $3.066,37^{\mathrm{ns}}$ \\
\hline Água disponível & 3 & $2,79^{* *}$ & $3,13^{* *}$ & $1.919 .667,92^{* *}$ & $1.781 .787,59^{* *}$ \\
\hline Água Disponível x Cultivar & 3 & $0,05^{\mathrm{ns}}$ & $0,06^{\mathrm{ns}}$ & $34.274,86^{\mathrm{ns}}$ & $3.448,79^{\mathrm{ns}}$ \\
\hline Blocos & 2 & $0,70^{\mathrm{ns}}$ & $0,37^{\mathrm{ns}}$ & $18.450,58^{\mathrm{ns}}$ & $2.606,55^{\mathrm{ns}}$ \\
\hline Resíduo & 14 & 0,61 & 0,29 & $16.155,68$ & $28.303,85$ \\
\hline $\mathrm{CV}(\%)$ & & 25,87 & 9,10 & 9,64 & 13,15 \\
\hline Regressão Polinomial Linear & & $7,80^{* *}$ & $9,10^{* *}$ & $5.623 .894,96^{* *}$ & $5.053 .526,09^{* *}$ \\
\hline Regressão Polinomial Quadrática & & $0,01^{\mathrm{ns}}$ & $0,04^{\mathrm{ns}}$ & $33.530,61^{\mathrm{ns}}$ & $11.543,95^{\mathrm{ns}}$ \\
\hline Regressão Polinomial Cúbica & & $0,55^{\mathrm{ns}}$ & $0,26^{\mathrm{ns}}$ & $101.578,21^{*}$ & $280.292,74^{* *}$ \\
\hline Resíduo & & 0,61 & 0,29 & $16.155,68$ & $28.303,85$ \\
\hline Cultivares & & \multicolumn{2}{|c|}{ Médias da área foliar $\left(\mathrm{m}^{2}\right)$} & \multicolumn{2}{|c|}{ Médias da fitomassa(g) } \\
\hline Nordestina & & $2,82 \mathrm{a}$ & $2,85 \mathrm{a}$ & $1.272,31 \mathrm{a}$ & $1.267,74 a$ \\
\hline Paraguaçu & & $3,22 \mathrm{a}$ & $3,14 \mathrm{a}$ & $1.363,46 \mathrm{a}$ & $1.290,35 a$ \\
\hline DMS & & 0,68 & 0,47 & 111,29 & 147,31 \\
\hline
\end{tabular}

GL - grau de liberdade; Significativo a $0,05\left(^{*}\right)$ e a $0,01\left(^{* *}\right)$ de probabilidade; (ns) não significativo; CV - coeficiente de variação; DMS - diferença mínima significativa; médias seguidas de mesma letra na vertical não diferem entre si $(\mathrm{p}<0,05)$.

Na Figura 3, são apresentadas as regressões com suas respectivas curvas e equações para os diferentes ciclos de avaliação da área foliar, constatando-se, aos 180 DAS, um efeito linear no crescimento com o aumento da disponibilidade de água no solo, de 0,0256 $\mathrm{m}^{2}$ por aumento unitário do percentual de água no solo, em volume. No segundo ciclo, verificou-se comportamento linear crescente na medida em que se elevou o conteúdo de água disponível do solo durante todo o ciclo da cultura; a área foliar, aos $180 \mathrm{DAP}$, atingiu valores de $3,74 \mathrm{~m}^{2}$ para a condição sem estresse 
hídrico (100 \% da AD). O aumento unitário da área foliar foi de 0,0276 $\mathrm{m}^{2}$ à medida que se elevou o percentual unitário de água aos 180 DAP.

LACERDA et al. (2009), trabalhando em casa de vegetação, verificaram incremento de $37,60 \%$ na AF da cultivar BRS Nordestina, irrigada com água de abastecimento, aos 120 DAS, em plantas do tratamento com $70 \%$ da $\mathrm{AD}$, em comparação às plantas adequadamente irrigadas (100\% AD), corroborando os resultados desta pesquisa.

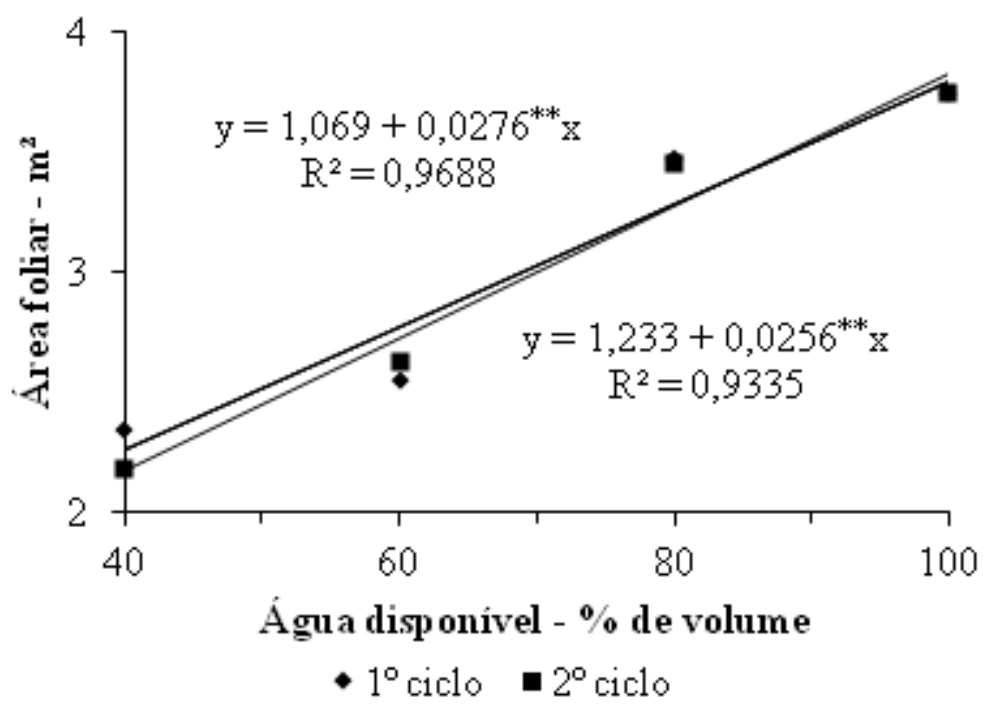

FIGURA 3. Área foliar da mamoneira em função da água disponível no solo. Leaf area of Castor bean versus available soil water.

BARROS JÚNIOR et al. (2008), trabalhando em casa de vegetação, observaram que reduções da área foliar aparecem mais precocemente, quanto menor for o nível de água disponível no solo. LACERDA (2010) encontrou, em experimento realizado em campo, que o aumento da área foliar também evoluiu de forma linear e crescente, com o avanço do ciclo da cultura, atingindo valores de 6,12 $\mathrm{m}^{2} \mathrm{e}$ 7,94 m², aos 180 DAS, para a condição sem estresse hídrico (100\% AD), nos solos cujo teor de matéria orgânica foi mantido a 5,0 g. $\mathrm{kg}^{-1}$ e $25,0 \mathrm{~g} . \mathrm{kg}^{-1}$, respectivamente.

\section{Fitomassa da parte aérea}

São apresentados na Tabela 3 os dados do experimento relativo à fitomassa da parte aérea, onde foi observado que não houve diferença significativa entre as cultivares testadas quando as mesmas foram submetidas a diferentes níveis de água disponível no solo.

Observou-se um efeito significativo da água disponível no solo ao nível de $1 \%(\mathrm{P}<0,01)$, com o incremento do nível de AD. Os acréscimos sobre a fitomassa das plantas submetidas ao nível $100 \%$ de AD, relativos a 40; 60 e 80\% de AD, foram 62,80; 50,56 e 19,81\%, aos 180 DAS, no final do primeiro ciclo, superior aos tratamentos de 40; 60 e $80 \%$ de AD. A maior fitomassa foi de $100 \%$ de $\mathrm{AD}$, com 1.975,62 gramas (Tabela 3).

A fitomassa produzida pelas plantas cultivadas no solo com $100 \%$ de água disponível (1.868,29 g), aos 180 DAP, em segundo ciclo, foi superior em 60,7; 51,5 e 14,0\% à fitomassa produzida pelas plantas cultivadas em solo com 40; 60 e $80 \%$ de $\mathrm{AD}$, respectivamente; esses resultados apresentam-se semelhantes aos da primeira fase do experimento, demonstrando o vigor da cultivar estudada para condições de rebrote.

De acordo com LACERDA (2010), em experimento realizado em campo com a cultivar BRS 188 - Paraguaçu, foram encontrados resultados onde a água disponível no solo influenciou significativamente $(\mathrm{p}<0,01)$ na produção de fitomassa da mamoneira, observando que a fitomassa das plantas, na capacidade de campo (100\% AD), foi 40,4; 27,9 e 15,7\%, superior à fitomassa 
produzida pelas plantas no solo com 70; 80 e 90\% de AD, aos 180 DAS, respectivamente. BARROS JÚNIOR et al. (2008), trabalhando com a mesma cultivar de mamona em casa de vegetação, até os 180 dias, obtiveram 348,0\% a mais de fitomassa total da parte aérea da raiz, quando mantiveram o solo com a capacidade de campo (1.393,45 g), comparado com a fitomassa da mesma cultivar submetida a $40 \%$ de $\mathrm{AD}(11,15 \mathrm{~g})$, confirmando a tendência dos resultados obtidos no presente ensaio.

Na Figura 4, são visualizadas as regressões para o fator água disponível, nas quais se verifica um aumento crescente e linear de 21,65 g por aumento unitário do percentual de água no solo, ao nível de $1 \%(\mathrm{p}<0,01)$ ao final do primeiro ciclo. No segundo ciclo, o aumento unitário da fitomassa produzida pela cultivar de mamona foi 20,52 g à medida que se elevou o percentual unitário de água no solo, aos 180 DAP, com uma diferença, a menor, de 1,13 g a mais no primeiro ciclo.

AZEVEDO et al. (2007) ressaltaram que um dos efeitos da poda é a redução do porte da planta, o qual confirma os observados no presente estudo. Nos tratamentos-testemunha e poda aos 18 nós, as plantas apresentaram maior crescimento.

Segundo DINIZ et al. (2009), trabalhando em experimento de campo com a cultivar BRS 149-Nordestina, em condições de sequeiro, em Quixadá, Ceará, a poda da gema apical no $6^{\circ}$; $10^{\circ}$ e $14^{\circ}$ nó do ramo principal reduziu o porte da planta, em relação ao tratamento-testemunha, mas não afetou a produtividade da cultura.

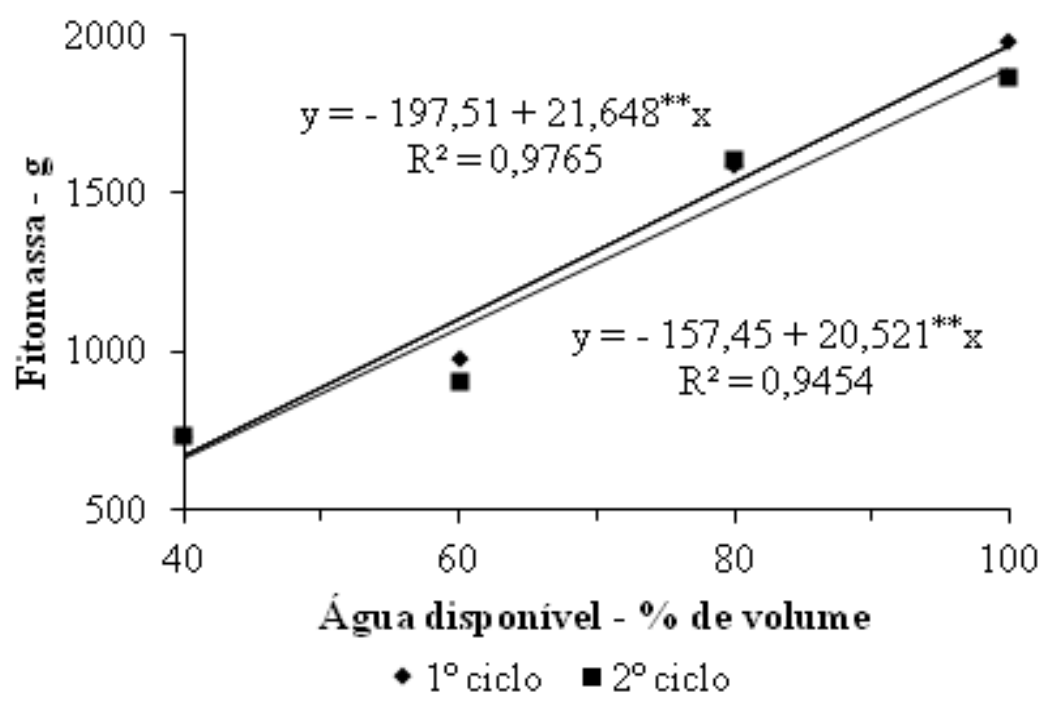

FIGURA 4. Fitomassa da parte aérea da mamoneira em função da água disponível no solo. Aerial Phytomass of Castor bean versus available soil water.

\section{CONCLUSÕES}

- As cultivares de mamona em ambos os ciclos de crescimento não apresentaram diferenças significativas quanto à altura de plantas, diâmetro do caule, área foliar e fitomassa da parte aérea, aos 180 dias após a semeadura - primeiro ciclo e 180 DAP - segundo ciclo.

- Quando submetidos a diferentes conteúdos de água disponível no solo, houve aumento significativo da altura da planta, diâmetro do caule, área foliar e fitomassa da parte aérea, o que caracteriza resposta positiva da cultura quando se eleva o teor de água disponível (AD) nos dois ciclos da cultura.

- A altura de planta, o diâmetro caulinar e a área foliar das cultivares de mamoneira são reduzidos, quando as plantas dispõem de menos de $60 \%$ de $\mathrm{AD}$ no solo. 
O similar comportamento da mamona, em ambos os ciclos, mostram a viabilidade da adoção da prática de poda drástica para viabilizar o rebrote, pois possibilita a diminuição dos custos de produção, com a compra de sementes, tratos culturais iniciais (preparo do solo e plantio) e erradicação dos restos culturais.

\section{REFERÊNCIAS}

AZEVEDO, D. M. P. de; BELTRÃO N. E. de M; SEVERINO, L. S. Manejo cultural In: AZEVEDO, D. M. P.; BELTRÃO, N. E. de M. (Ed.). O agronegócio da mamona no Brasil. Brasília: Embrapa Informação Tecnológica, 2007. p.223-253.

BARRETO, H. B. F.; MEDEIROS, J. F. de; MAIA, P. de M. E.; COSTA, E. M. da; OLIVEIRA, L. A. de A. Crescimento de acessos de mamona sob condições de irrigação em Mossoró-RN. Revista Verde, Mossoró, v. 5, n. 2, p. 123-130, 2010.

BARROS JUNIOR, G.; GUERRA, H. O. C.; CAVALCANTI, M. F.; LACERDA, R. D. de. Consumo de água e eficiência do uso para duas cultivares de mamona submetidas a estresse hídrico. Revista Brasileira de Engenharia Agrícola e Ambiental, Campina Grande, v. 12, n. 4, p. 350-355, 2008.

BELTRÃO N. E. de M; BRANDÃO, Z. N.; AMORIM NETO, M da S.; ARAÚJO, A. E.; AMARAL, J. A. B. do; Clima e solo In: AZEVEDO, D. M. P.; BELTRÃO, N. E. de M. (Ed.). O agronegócio da mamona no Brasil. Brasília: Embrapa Informação Tecnológica, 2007. p.73-93.

BERNARDO, S. Manual de irrigação. ${ }^{\mathrm{a}}$ ed. Viçosa: UFV, 2008. 620p.

CRUZ, T. V.; PEIXOTO, C.P.; MARTINS, M. C. Crescimento e produtividade de cultivares de soja em diferentes épocas de semeadura no Oeste da Bahia. 2010. Scientia Agraria, Curitiba, v.11, n.1, p.33-42, jan./fev. 2010.

DINIZ, B. L. M. T.; TÁVORA, F. J. A. F.; DINIZ NETO, M. A. Manipulação do crescimento da mamoneira através da poda em diferentes densidades populacionais. Revista Ciências Agronômicas, Fortaleza, v.40, n.4, p.570-577, out./dez., 2009.

DINIZ NETO, M. A., TAVORA, F. J. A.F., CRISÓSTOMO, L. A., DINIZ, B. L. M. T. Adubação NPK e épocas de plantio para mamoneira. I - Componentes da produção e produtividade. Revista Ciências Agronômicas, Fortaleza, v.40, n.4, p.578-587, out./dez., 2009.

EMBRAPA. Centro Nacional de Pesquisa de Solos. Manual de métodos de análise de solo. 2. ed. rev. atual. Rio de Janeiro, 1997. 212p. ( Documentos, 1)

FREITAS, C. A. S. de; BEZERRA, F. M. L.; SILVA, A. R. A. da; PEREIRA FILHO, J. V.; FEITOSA, D. R. C. Comportamento de cultivares de mamona em níveis de irrigação por gotejamento em Pentecoste, CE. Revista Brasileira de Engenharia Agrícola e Ambiental, Campina Grande, v.14, p.1059-1066, 2010.

LACERDA, R. D. de; GUERRA, H. O.; BARROS JÚNIOR, G. Influência do déficit hídrico e da matéria orgânica do solo no crescimento e desenvolvimento da mamoneira BRS 188 - Paraguaçu. Revista Brasileira de Ciências Agrárias, Recife, v. 4, n. 4, p. 440-448, out./dez., 2009.

LACERDA, R. D. de. Resposta da mamona à disponibilidade de água e matéria orgânica no solo, em dois ciclos com manejo de poda. 2010. 141 f.. Tese (Doutorado em Engenharia Agrícola) Universidade Federal de Campina Grande, Campina Grande, 2010.

MEDICI, L. O. et al. Stomatal conductance of maize under water and nitrogen deficits. Pesquisa Agropecuária Brasileira, Brasília, v. 42, n. 4, p. 599-601, 2007.

NASCIMENTO, M. B. H. do; LIMA, V.L.A. de; BELTRÃO, N.E. de M.; SOUZA, A.P. Utilização de água residuária e biossólido na cultura da mamona: Crescimento e desenvolvimento. In: 
CONGRESSO BRASILEIRO DE MAMONA - ENERGIA E SUSTENTABILIDADE, 1., 2004. Anais... Campina Grande: Embrapa Algodão, 2004. 5p.

OLIVEIRA, C. J. da S.; SOUSA, P. S. de; MESQUITA, T. de O.; PORTO FILHO, F. de Q.; MEDEIROS, J. F. de. Crescimento de cultivares de mamoneira sob condições de irrigação em Mossoró-RN. Revista Caatinga, Mossoró, v.22, n.4, p.27-33, out-dez. 2009.

RODRIGUES, L. N.; NERY, A. R.; FERNANDES, P. D.; BELTRÃO, N. E. M.; GHEYI, H. R. Crescimento e produção de bagas da mamoneira irrigada com água residuária doméstica.Revista Brasileira de Engenharia Agrícola e Ambiental, Campina Grande, v.13, Supl.0, p.825-835, 2009.

SAMPAIO FILHO, O. M.; SILVA, S. A.; BAHIA, H. F.; SILVA, M. S. da; CARVALHO, D. dos S. Análise descritiva de cultivares de mamoneira em dois anos de cultivo no recôncavo baiano. Revista Brasileira de Educação Ambiental, Rio Grande, v.6, n.1, p.28-34, 2011.

SANTOS, J. W. dos; ALMEIDA, F. de A. C.; BELTRÃO, N. E. de M.; CAVALCANTI, F. B. Estatística experimental aplicada. 2.ed. rev. e aum. Campina Grande: Embrapa Algodão/Universidade Federal de Campina Grande, 2008. 461 p.

SILVA, S. M. S.; ALVES, A. N.; GHEYI, H. R.;BELTRÃO, N. E. de M.; SEVERINO, L. S.; SOARES, F. A. L. Desenvolvimento e produção de duas cultivares de mamoneira sob estresse salino. Revista Brasileira de Engenharia Agrícola e Ambiental, Campina Grande, v.12, n.4, p.335342, 2008.

WENDT, C. W. Use of a relationship between leaf length and leaf area of cotton (Gossypium hirsuntum L.). Castor (Ricinus communis L.). and Sorghum (Sorghum vulgare L.). Agronomy Journal, Madson, v. 59, p.485-487, 1967. 